\title{
Conglomerates: The new trend of expansions
}

\author{
Ashok Panigrahi ${ }^{1 *}$, Parth Mansinghka², Piyush Gupta ${ }^{3}$ \\ ${ }^{\mathbf{1}}$ Associate Professor, ${ }^{\mathbf{2}, 3}$ Student, ${ }^{\mathbf{1}}$ Dept. of Technology Management, ${ }^{\mathbf{1} 2}$ SVKM's Narsee Monjee Institute of Management Studies, Shirpur, \\ Maharashtra, India, ${ }^{3}$ Institute of Cost Accountants of India \\ *Corresponding Author: Ashok Panigrahi \\ Email: panigrahi.ak@gmail.com
}

\begin{abstract}
The goal for making this paper on conglomerates is to introduce the rising trend of conglomerates in big companies. This paper shall introduce what might be the reasons for Conglomerates, and their increasing trends. What are the benefits that companies enjoy being a conglomerate and what might be the disadvantages for it too? Further, the conglomerates are classified in two types, which are also explained with examples. Then we have taken examples of many companies to explain details about conglomeration. At the end there is a case study on Facebook, about how it acquired some companies and what the effects on both companies actually were, in terms of growth and benefit.
\end{abstract}

Keywords: Conglomerate, Market share, MNC, Facebook, Expansion, Diversification.

\section{Introduction}

A Conglomerate company is generally a very large and a MNC, which consists of multiple business entities or companies itself, which might be acquired by the parent company or might be just a subsidiary of the parent company. The companies don't start as conglomerates, they are just standalone companies at the start, i.e. just like the normal startups. The different child companies might be various types of industries (might be entirely different) working under one parent company. The conglomerate parent companies are mostly unknown to common people even if they are daily users of the products of the child companies in some or the other way. Conglomerates have now become a common trend among companies, which might be because of some reasons such as, exploring new areas, as a measure for extreme risks in the BEAR-BULL market, capturing the market share in the same field as much as possible etc. which will be discussed in detail later on along with some examples.

\section{Reasons behind growing trend of conglomerates}

There is a variety of reasons for companies being conglomerates out of which some are:

\section{Expanding to new possible business areas}

This process of companies wanting to expand to new areas or business sectors is known as DIVERSIFICATION. This is done to avoid some possible risks that might come in their current business line. Here the companies try to invest in some small profit making companies of some other sector of their own which might be through:

1. Buying the company or,

2. Getting more than $50 \%$ stakes to hold decision making power.

The companies do so as a PROVISION for possible future losses that might incur in their present working field. This can also be known as CUSHIONING for risks in the BEAR-BULL markets. The Bear market refers to a pessimistic \& falling market whereas, Bull market refers to an optimistic \& rising market. If a company is a conglomerate and holds two companies (for example companies A and B), even if company A goes in loss, there is still a chance to recover losses by making profits by the $\mathrm{B}$ company.

\section{Capturing maximum possible market share}

This is done by some companies so as to boost the profits in a particular sector by grabbing the maximum control over the market. Example can be the BBK Electronics being the parent company for oppo and vivo. This can also be done to get the market share of the various types of public in the market. The Bottom-line, according to us, can be:

"If most of our competitors are also us, then whichever people buy, profit is ours only!"

\section{Providing an internal market}

The concept of Internal market might seem a little confusing, but it a very important opportunity for both small companies and the big firms.

Basically whenever there is an idea for a startup or a new business venture, even if the group has good technology for it, then also there are less chances of it being successful because of the lack of a certain factor known as Capital. In order to go on with a good but high risk idea, people need a good amount of money which is given by the big ventures like Tata, Virgin group etc. Along with capital, they also need some field experience and knowledge to scale up their idea. Recent reports say that Tata Group enrolled 54,000 users of InnoVerse (their idea sharing platform) out of which 2,345 ideas were selected so far, and 344 have been implemented.

There is another factor that is talent management. Every person wants to be his/her own boss. There might be people in our organization that we don't want to lose due to their high skillset or expertise in their field. They might be willing to start their own startups. So if company where he/she is working offers to launch his idea as a subsidiary of the company, then that option isn't that bad. This is also one of the possible reasons for Conglomerates. 
Types of conglomerates

We have categorized conglomerates broadly in two categories:

1. Within the same sector or,

2. Outside the sector.

We will now give a detailed description of both of them with suitable cases:

\section{Within the same sector}

Here in this type, the companies form or acquire companies in the same sector they are working in. The same sector might mean even the similar kind of product differing each other with cost or specifications. The reasons for this sector can be:

1. Gathering maximum market control.

2. Fulfill certain public demands.

3. Make different products for different profile or sectors of public demand.

The first example that comes to mind is of BBK electronics being the parent company of Oppo and Vivo, and OnePlus further being a subsidiary of Oppo.

In a market Oppo sells smartphones marketing its phones in the name of making cheaper phones with great specifications at that price and creating amazing selfie experiences, whereas, Vivo markets its phones by aiming at quality products and superior services available at various price ranges. Also vivo positions itself as a perfect selfie smartphone, whereas, OnePlus comes in with totally different marketing strategy and set of customers in mind. The OnePlus phones focus on the premium segment; focuses on delivering powerful phones might be in terms of security, Camera, Gaming experience etc. that too in an Android environment. This strategy appeals to the Android preferring audiences who are looking for a powerful smartphone but are not ready to switch to IOS for that sake. So it is somewhat cheaper option as compared to iPhones and also a very powerful one.

According to certain reports, OnePlus was the market leader with $36 \%$ market share in the high-end segment in India followed by Apple at $30 \%$ and then Samsung by $26 \%$ at the end of Dec2018.

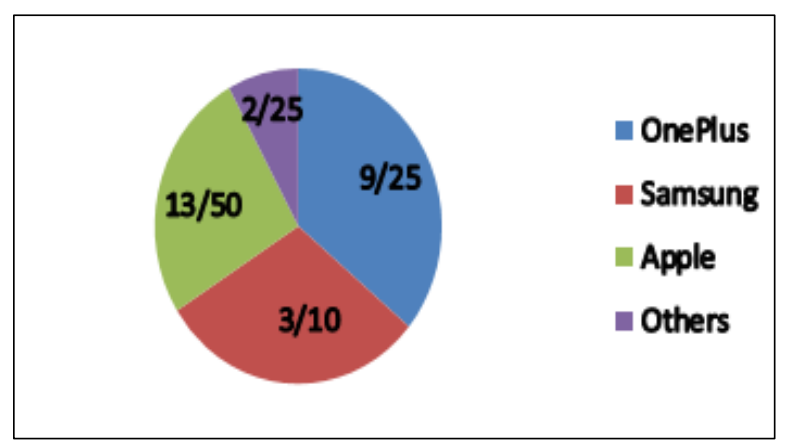

Fig. 1: Market share in high-end segment at end of December 2018.

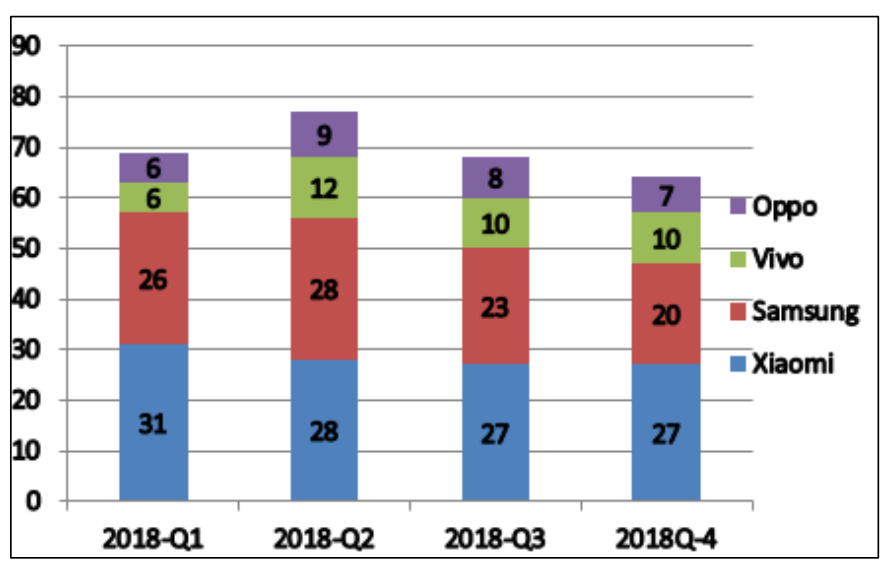

Fig. 2: Smartphone-market-share-in-India 2018.

Another Example of this sector can be the conglomerates of Volkswagen group. The Volkswagen group has several child companies under the name Volkswagen AG. The company has companies like Porsche, Lamborghini, Bentley, Audi, Scania AB, Volkswagen passenger cars etc. under it. So the Volkswagen group has various companies under it in different sectors like Lamborghini, Porsche has customers who prefer luxury cars, Audi can be considered as an example to lower priced luxury cars, Volkswagen passenger cars for the common man and Scania $\mathrm{AB}$ for the manufacture of commercial vehicles etc.. Hence it holds control over various kinds of public in the same market.

Some strategies developed by Volkswagen:

1. Selection of strong automotive brands and making them efficient and more operational has made company more advanced.

2. It has also made itself more financially secure with such a wide range of companies under the umbrella and many companies have no doubt of merging within it.

3. With such a brand funding, it has came up with a remarkable amount of economic operational cost which helps in keeping other brands their operational cost as low.

\section{Outside the sector}

In this type of conglomerates, the companies make subsidiaries or acquire companies outside of their own sector, i.e. the different child companies might make products which totally differ from each other. Hence this is also known as PURE conglomerates. The reasons for outside the sector might be:

1. Expansion of the business.

2. As a cushioning for possible risks in the current sector.

The examples of this type can be the child companies of Tata. For example, Tata has a wide range of conglomerates under it. Many of them might be its own subsidiaries, acquired companies or might be the partnership with some other companies. Subsidiaries of Tata include following sub headings: Companies with Tata name and without Tata name. 
Some Companies with Tata name are:

1. Tata Motors: Tata Motors cars, Jaguar Land Rover, Tata Hispano etc.,

2. Tata Consultancy services(TCS),

3. Tata Teleservices: Tata Docomo,

4. Tata Sky,

5. Tata salt,

6. Tata Starbucks- a joint venture of Tata Global Beverages and Starbucks etc.

Some Companies without Tata name are:

1. Taj hotels resorts and palaces,

2. Air Asia India- a joint venture with Air Asia,

3. Tanishq,

4. Voltas,

5. Titan industries,

6. Indicash atm etc.

As on March 31, 2018, the combined market capitalism of the 28 publically-listed Tata enterprises accounted to about $\$ 145.3$ billion.

\section{Case Study - Facebook}

Facebook, one of the most renowned names in the world of social media, is a social networking website founded by Mark Zuckerberg. When it comes to the technological world, it comes in "THE BIG FOUR" technology companies, the other three being Amazon, Apple and Google.

Till date, it is the social media platform not only in terms of the maximum number of active users, but also in terms of revenue.

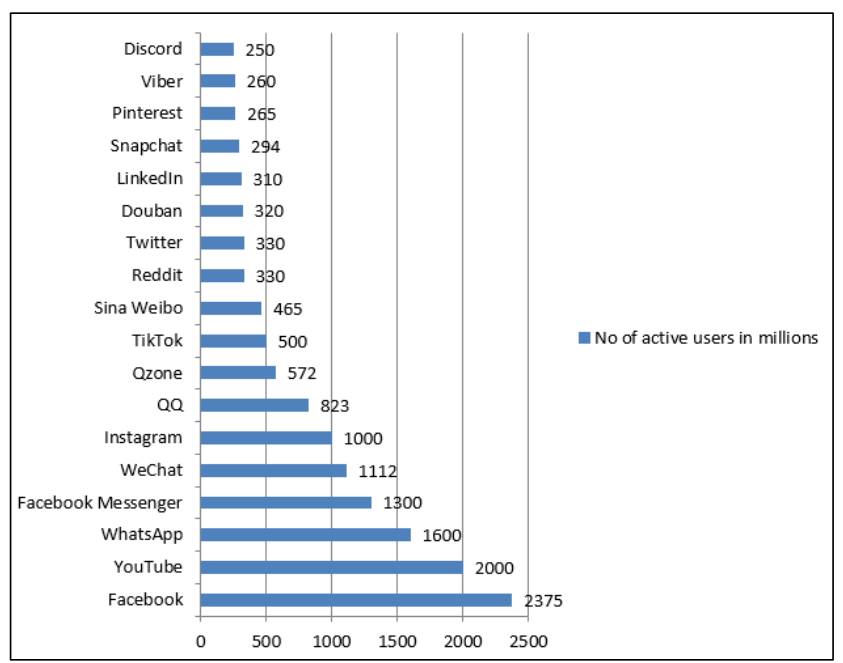

Fig. 3: Most popular social networks as of July 2019 according to no of active users (in millions).

Facebook was originally started as a single company, but it is not the same case anymore. As some great personality once said: "Change is the only constant thing!", there were need of changes due to user demand and the competitive environment.

So Facebook acquired certain companies for the sake of being in market some of the famous and important acquisitions are:
1. The Friend Feed Company was acquired on August 10, 2009. It is a real time social network aggregator.

2. Instagram was acquired by Facebook on April 9, 2012.

3. Whatsapp was acquired by Facebook on February 19, 2014.

4. Oculus VR acquisition on March 25, 2014.

Oculus VR acquisition was very different from other acquisitions done by Facebook as this one isn't related to its own SOCIAL MEDIA SECTOR. Hence this case study shows how Facebook did both the within its own sector and outside the sector as well!

Now let's take one merger i.e. the INSTAGRAM merger with Facebook and see how both of them got benefitted.

Let us first see how Facebook got benefitted:

1. Increased revenues, as now the revenues of both, Instagram and Facebook went to Facebook only.

2. Reduced Market risk and Investment risk as even if the no of users in Facebook went down, there is a chance that either users might be switching to Instagram so anyways the risk was reduced.

Now let us see the benefit that Instagram had after the acquisition by Facebook.

The following graph shows that how the no of active users went up after the acquisition by Facebook to 1 Billion:

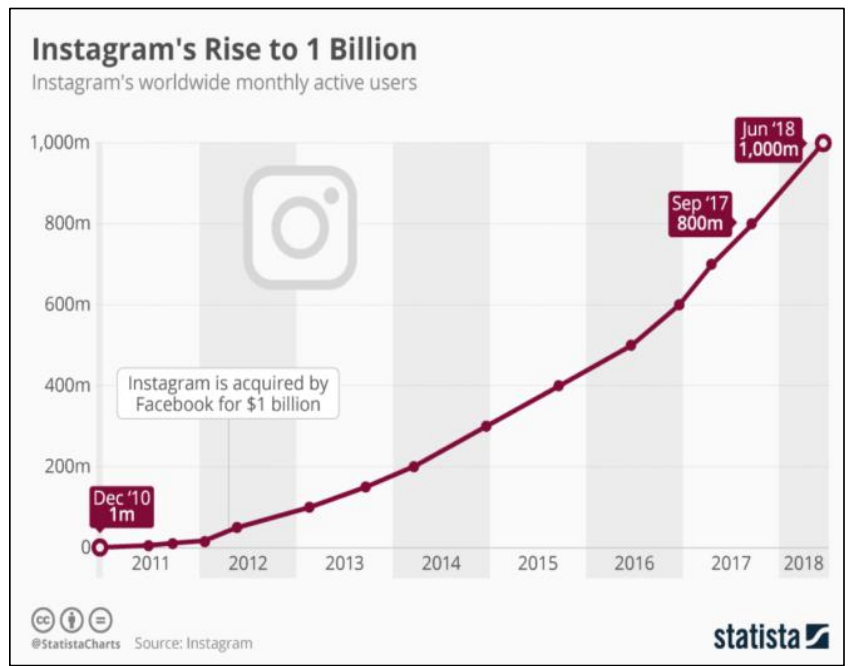

Fig. 4: Source:

https://www.statista.com/chart/9157/instagram-monthlyactive-users/.

\section{Conclusion}

This paper has given a brief study of conglomerates, introduced some key reasons for the conglomerate mergers and acquisitions, introduced some new type of classification for the conglomerates and described it in the real world environment with the help of suitable examples. Then we took a case study of Facebook for its various acquisitions and saw the benefits that the companies at both ends, i.e. The Parent Company and The child companies enjoyed. This paper is made in an informative manner so that the people who read it should understand the meaning of conglomerates 
and become aware of the strategies that companies adapt in today's competitive world. Hence we conclude this paper by saying that the trend that had gone for conglomerates is back and many companies are enjoying the vast benefits of conglomerates.

\section{Source of Funding}

None.

\section{Conflict of Interest}

None.

\section{References}

1. https://www.statista.com/chart/9157/instagram-monthlyactive-users/.

2. https://efinancemanagement.com/mergers-andacquisitions/conglomerate-merger.
3. https://www.forbes.com/sites/christianstadler/2015/11/05/three -reasons-why-conglomerates-are-back-infashion/\#5b386b573be6.

4. https://en.wikipedia.org/wiki/List_of_mergers_and_acquisition s_by_Facebook.

5. https://www.dreamgrow.com/top-10-social-networking-sitesmarket-share-of-visits/.

How to cite: Panigrahi A, Mansinghka P, Gupta P. Conglomerates: The new trend of expansions. J Manag Res Anal. 2020;7(3):127-30. 